\title{
Utility of sonohysterography in evaluation of patients with abnormal uterine bleeding
}

\author{
Mohamed SM1, Anyona $\mathrm{AA}^{2}$, Onyambu $\mathrm{CK}^{2 *}$, Muriithi IM² and Mutala TM² \\ ${ }^{1}$ Consultant Radiologist, The Mombasa Hospital, Mombasa, Kenya \\ ${ }^{2}$ Department of Diagnostic Imaging and Radiation Medicine, University of Nairobi, Kenya
}

\begin{abstract}
Introduction: Abnormal Uterine Bleeding (AUB) is one of the most common gynecological problems faced by women especially in the reproductive age as well as post-menopausal state. Several imaging modalities have been used to investigate this problem including ultrasound. Sonography is the most easily accessible and easy to use modality for the initial management of AUB. Both Transvaginal Sonography (TVS) and transabdominal sonography are being used in many departments as the initial imaging modality. Though proven useful in the investigation of AUB, a normal finding in these modalities doesn't always rule out endometrial causes of AUB. Sonohysterography (SHG) enables better visualization of the endometrium and the endometrial cavity and therefore characterization of endometrial abnormalities.
\end{abstract}

Objective: To determine the sonohysterographic findings in patients presenting with AUB in Kenyatta national hospital.

Materials and methods: A total of 87 women with abnormal uterine bleeding who satisfied the inclusion criteria were enrolled in this study. A prior transabdominal and transvaginal sonography followed by a sonohysterography was performed in all cases. The presence of focal endometrial and subendometrial lesions and the descriptions of lesions were done.

Results: The age of women presenting with AUB was between 20 years and 45 years with the mean age of $31.57 \pm 6.06$ years. The most common symptom was menorrhagia (25\%) and the least was oligomenorrhea. Out of the 87 subjects, uterine fibroids were seen in 6 of the patients with menometrorrhagia, and 1 of the patient with metrorrhagia. TVS done prior to the SHG showed abnormalities within the endometrium in 8/87(9\%). These included endometrial hyperplasia, fibroids, and floating clot within the uterine cavity. TVS provided false negative in $6(7 \%)$ cases out of the normal 79 cases. All the cases of partial endometrial synechiae were seen in patients presenting with oligomenorrhea. Out of the 13 abnormalities seen on SHG, 3(23\%) were accurately detected on TVS. All the 3 were endometrial hyperplasia. Out of the $8 / 87$ abnormalities provided by TVS, 3(37\%) were accurate while 5(62\%) were inconclusive.

Conclusion: Although TVS is a simple, minimally invasive low-cost technique initially used in evaluating AUB, however a normal TVS study doesn't exclude endometrial pathology as has been shown in previous and this study. SHG can detect abnormalities in an otherwise normal TVS. In addition, SHG is useful to further evaluate a positive finding on TVS. For this reason, SHG is recommended to be used in combination with TVS as an initial investigation of choice in patient with AUB.

\section{Introduction}

Abnormalities concerning menstruation are major psychosocial problem affecting many women regardless of the socio-economic status or geography. It is also one of the leading causes of co-morbidities, the most common being anemia.

A lot of effort has been put in investigating the probable causes of irregular menses, from laboratory investigations (including hormonal profiles, coagulation screenings, hemograms, etc) to different imaging modalities including sonography and MRI. The main challenge is to identify the treatable causes using the least invasive, least traumatic and most cost-effective methodology. Sonohysterography (SHG) has been recommended as part of the investigation of menorrhagia and menometrorrhagia [1-3].

When combined with endometrial biopsy, SHG is a useful technique for the evaluation of AUB [4]. It also shows very good correlation with hysteroscopic findings in the diagnosis of endometrial abnormalities in postmenopausal women [5]. SHG also allows better delineation of both the endometrium and focal abnormalities in the endometrial cavity, leading to hysteroscopically directed biopsy or resection. Color and pulsed Doppler may provide additional characterization of a focal endometrial abnormality by demonstrating vascularity [6].

Studies have shown that SHG can be used to complement regular ultrasonography and to substitute hysteroscopy, for the diagnosis of endometrial alterations that result in (AUB) [7].

Endometrial disorders may manifest with different signs and symptoms most common of which will be irregularity in the menstrual bleed or abnormal bleeding in the postmenopausal state. The most common initial modalities used to investigate are sonography and Hysterosalpingography (HSG). Sonography is mainly used to assess pathology of the female reproductive system including the uterus, endometrium and the ovaries. HSG mainly helps in assessing the

*Correspondence to: Callen Onyambu, Department of Diagnostic Imaging and Radiation Medicine, University of Nairobi, Nairobi, Kenya, E-mail: konyambu@ yahoo.com

Received: August 06, 2018; Accepted: August 24, 2018; Published: August 29, 2018 
endometrial cavity and condition of the fallopian tubes. HSG has minimal role in investigating endometrial abnormalities.

TVS is a sensitive method to evaluate endometrial lesions, but it does not always provide the physician with sufficient diagnostic information. SHG provides more information than TVS in evaluating those patients with abnormal uterine bleeding [13].

This study will further highlight the role and usefulness of SHG in management of patients with AUB in Kenya.

\section{Materials and methods}

Consecutive patients who were referred to the department for pelvic sonography due to AUB were selected after considering the inclusion criteria.

All selected patients were done preliminary transabdominal and TVS before the SHG. SHG was performed in all the patients including those with normal TVS findings. This was based on the finding of the study done by Kim S, et al [14] which showed that a normal TVS finding does not necessarily exclude endometrial pathology.

SHG was done following the 10 days rule (i.e. during the $10^{\text {th }}$ day from the $1^{\text {st }}$ day of the last menstrual period), with exceptions to the cases where the periods were prolonged or irregular in time. In these cases, the procedure was done when there was no active bleeding.

After obtaining informed consent, a structured questionnaire was filled out by the principal investigator or research assistant.

Preliminary transabdominal sonography followed by TVS was performed before the SHG. The external genitalia were cleaned with Betadine before insertion of the speculum. After visualization of the external cervical os, the os was also cleaned with antiseptic before insertion of the catheter. When the catheter is in situ, the balloon is inflated with approximately $3 \mathrm{ml}$ normal saline and the speculum removed. The TVS probe is then reinserted and while scanning the endometrium in a sagittal position normal saline is introduced into the endometrial cavity and the cavity is reassessed when it is filled with saline.

The US machine used was Phillips HD11. The transducer frequency was 3.5-5.0 MHz for transabdominal and 7.0-9.0 MHz for transvaginal sonography. Other material used for SHG included: Foley catheter size $6 \mathrm{Fr}$, normal saline, $3 \mathrm{cc}$ and $50 \mathrm{cc}$ syringes, disposable vaginal speculum, sterile gauze and betadine antiseptic.

All the SHG was performed by the researcher with assistance from the supervisors. The findings of all the procedures was then recorded and analyzed. The images were obtained in real time. The lesions were categorized as endometrial mass, submucosal fibroids, uterine synechiae, endometrial hyperplasia and subendometrial cysts.

Pathologic correlation was not done due to the infrequent and high cost of hysteroscopic guided biopsy in Kenya.

The study was done between July and December 2012.

Data was analyzed using SPSS version 18. Initially, a descriptive analysis of each demographic variable in the data set was conducted. This involved calculating means and Standard Deviations (SD) or ranges for each continuous variable for example age and reporting the sample means and SD. Categorical variables were described using frequency distribution and reported either as frequency tables or graphs.

\section{Results}

A total of 87 women who satisfied the inclusion criteria were evaluated. The age range was between 20 years and 45 years with the mean age of $31.57 \pm 6.06$ years. Sonohysterogrphy identified abnormal findings in 13/87 while TVS identified 8/87.

The most common symptom was menorrhagia (25\%) which was followed by menometrorrhagia (21\%), oligomenorrhea $(21 \%)$, metrorrhagia (20\%), polymenorrhea (8\%), and hypomenorrhea (6\%).

A single case was done during active bleeding due to the excessive prolonged uncontrolled bleeding. TVS in the case showed a mass within the endometrial cavity. Subsequent SHG done showed a floating clot within the uterine cavity.

In all the examinations, out of the 87 subjects, uterine fibroids were seen in 6 of the patients who presented with menometrorrhagia, and 1 of the patients who presented with metrorrhagia.

TVS done prior to the SHG showed abnormalities within the endometrium in $8 / 87(9 \%)$. Features of endometrial hyperplasia were seen in 5 of the 8 cases.

Out of the 5 cases of endometrial hyperplasia on TVS, 1 was confirmed to be endometrial thickness within normal limits, 1 showed an endometrial mass, and 3 were true endometrial hyperplasia.

In SHG, the case of endometrial mass on TVS was seen as a hyperechoic mass floating within the endometrial cavity with no attachment to the walls and showing no vascularity within it. This matched with a description of a floating blood clot.

The case of distorted endometrium by a uterine fibroid on TVS shows on SHG a mass isoechoic to the myometrium with an endometrium lining over it. $>50 \%$ of the mass was within the endometrial cavity. There was associated shadowing of the mass toward the myometrium. These were findings of submucosal fibroid.

The cyst within the endometrium was seen as a subendemetrial cyst on SHG (Figures 1-3).

In 6(8\%) out of the 79 TVS cases where the findings were normal, abnormality was found on SHG; 4(5\%) of the cases showed endometrial mass and 2(3\%) shows partial endometrial synechiae. All the cases of partial endometrial synechiae were seen in patients presenting with oligomenorrhea (Figures 4-9).

Out of the 13 abnormalities seen on SHG, 3(23\%) were accurately detected on TVS. All the 3 were endometrial hyperplasia.

Out of the 8 abnormalities demonstrated on TVS, 3(38\%) were accurate while 5(63\%) were either inconclusive or misleading.

In the case with uterine fibroid in which the endometrium was not well outlined, SHG was useful to define the endometrium thus confirming the presence of normal endometrium and the fibroid being intramural in location. (Tables 1 and 2) (Figures 10-12).

\section{Discussion}

AUB is an important and common problem encountered in gynecology practice. TVS is the first imaging modality of choice for the evaluation of uterine cavity in AUB. The setback is its limitations in detecting small lesions, location of fibroids and in differentiating diffuse and focal lesions [22].

There are different methods for detecting causes of AUB as a common chief complaint. SHG, in comparison to hysteroscopy, is less 

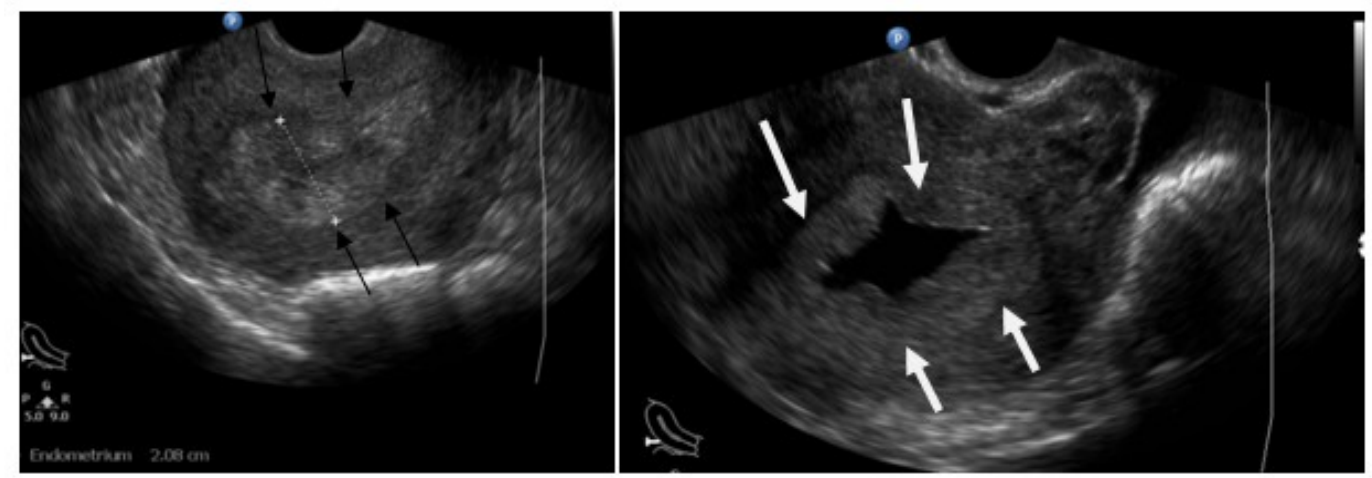

Figure 1. 42 years old woman who presented with menorrhagia.LEFT: TVS with endometrial thickness of 20.8mm (black arrows). Right: SHG confirmed the diagnosis of endometria hyperplasia (white arrows)
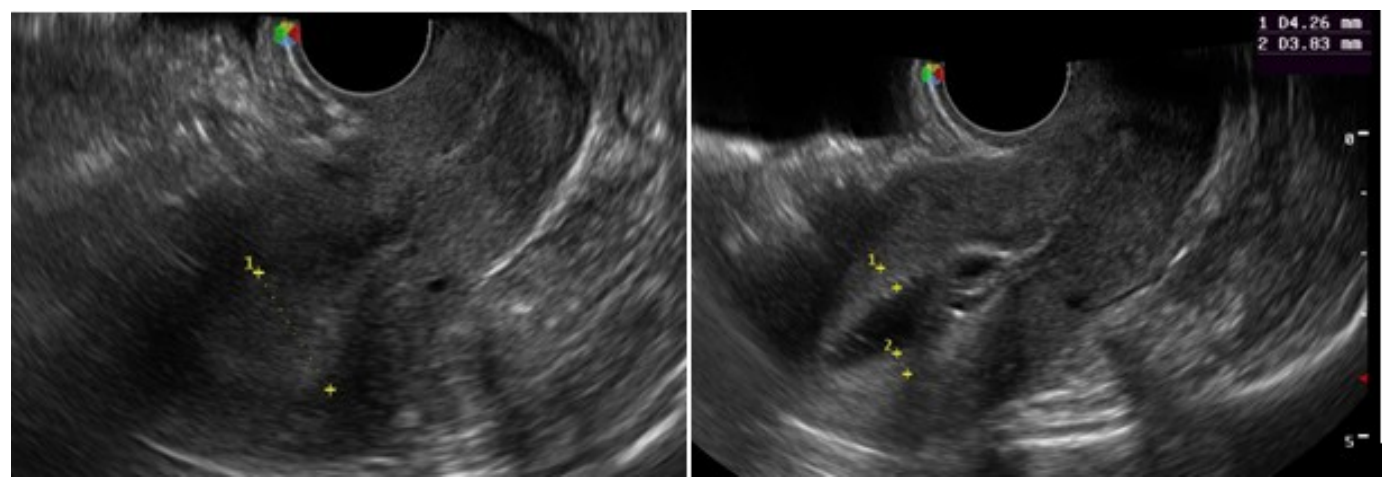

Figure 2. Patient who presented with menorrhagia. Left: Endometrial hyperplasia on TVS examination. Right: SHG shows normal single wall thickness of the endometrium
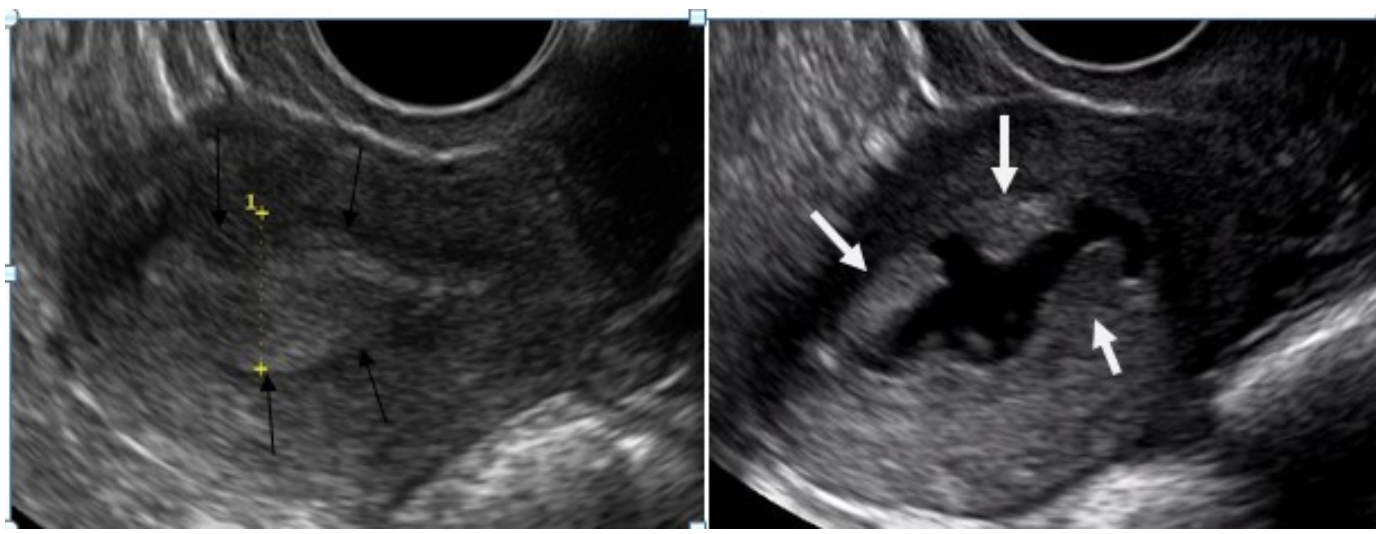

Figure 3. 42-years old woman who presented with menometrorrhagia.Left TVS shows endometrial thickness of 12.6mm (black arrows). A diagnosis of normal TVS finding was made. Right: SHG of the same patient shows 3 endometrial masses likely polyps. (white arrows)

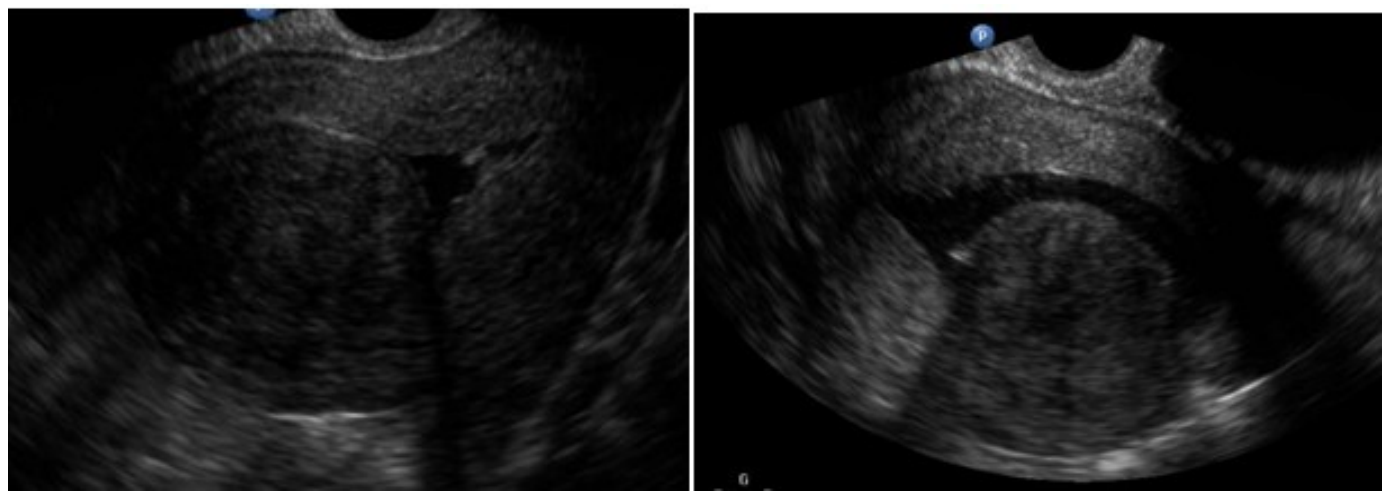

Figure 4. 30 years old patient who presented with menometrorrhagia.Left: fibroid seen but the exact location could not be made based on only TVS (white arrows). Note that the endometrial cavity could not be well outlined. Right: SHG showing clearly the fibroids location as submucosal (black arrows) 

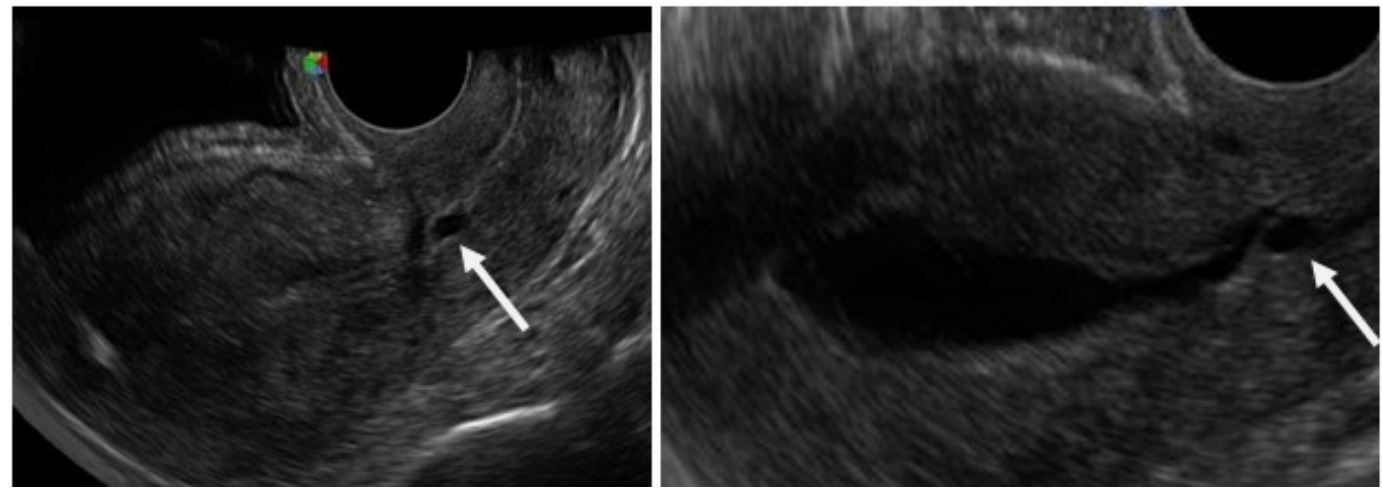

Figure 5. A 35 years old patient who presented with menometrorrhagia Left: TVS shows a cyst/loculated fluid collection within the endometrial cavity. Right: SHG showed that the cyst fluid collection was not within the endometrial cavity but at the subendometrial region. Note the endometrial lining clearly seen overlying the cyst
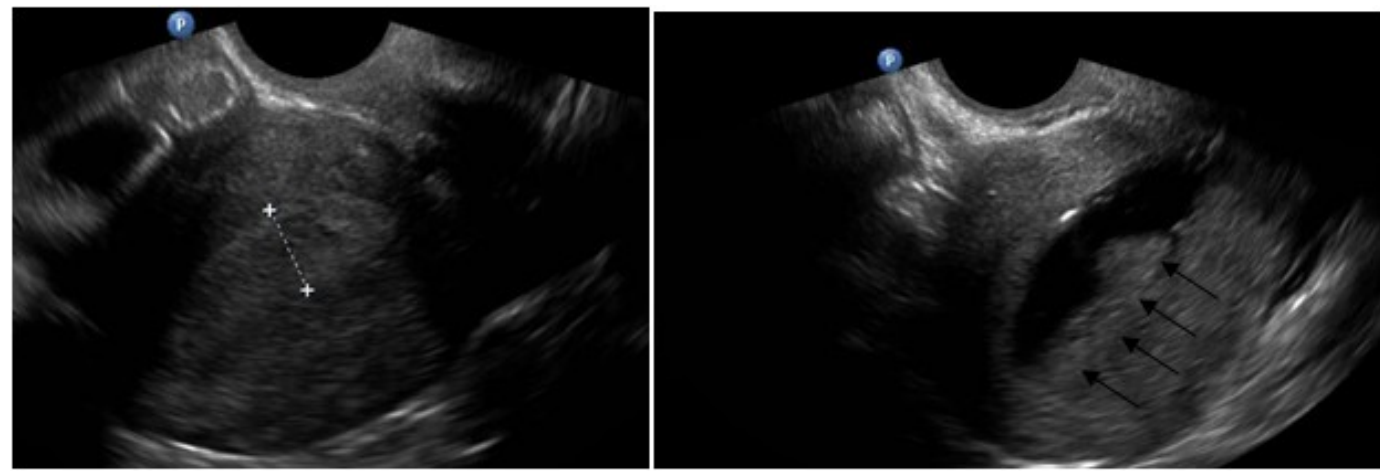

Figure 6. 24 years old patient who presented with menorrhagia Right: normal TVS with endometrial thickness of $9.86 \mathrm{~mm}$. Left: same patient's SHG shows a sessile endometrial lesion at the posterior wall of the uterine cavity (black arrows)
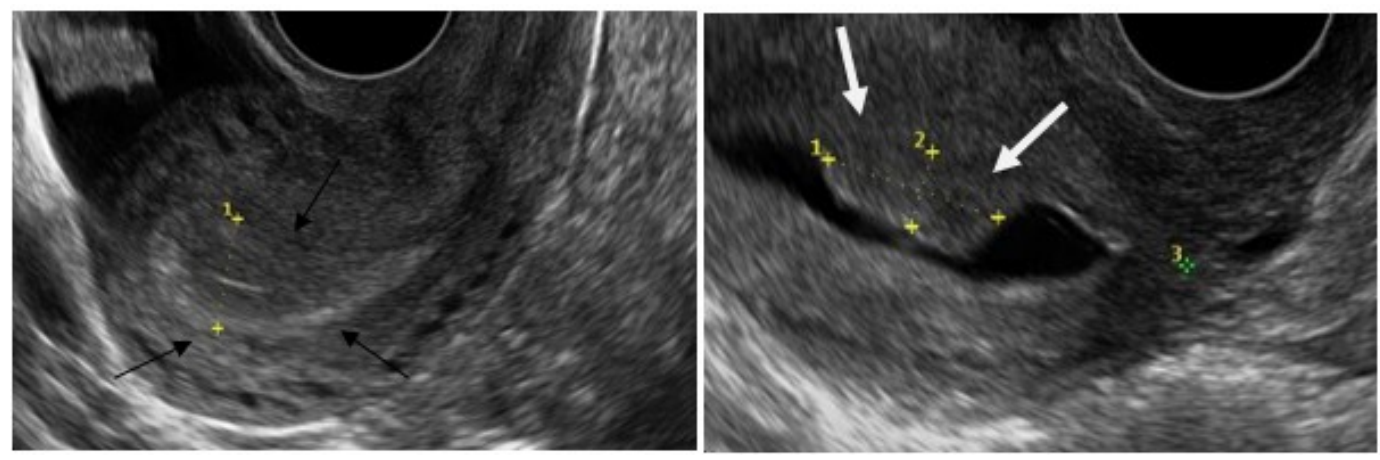

Figure 7. 24 years old patient who presented with menorrhagia. Right: normal TVS with endometrial thickness of $12.4 \mathrm{~mm}$ (black arrows). Left: same patient's SHG shows a sessile endometrial lesion at the anterior wall of the uterine cavity (white arrows)
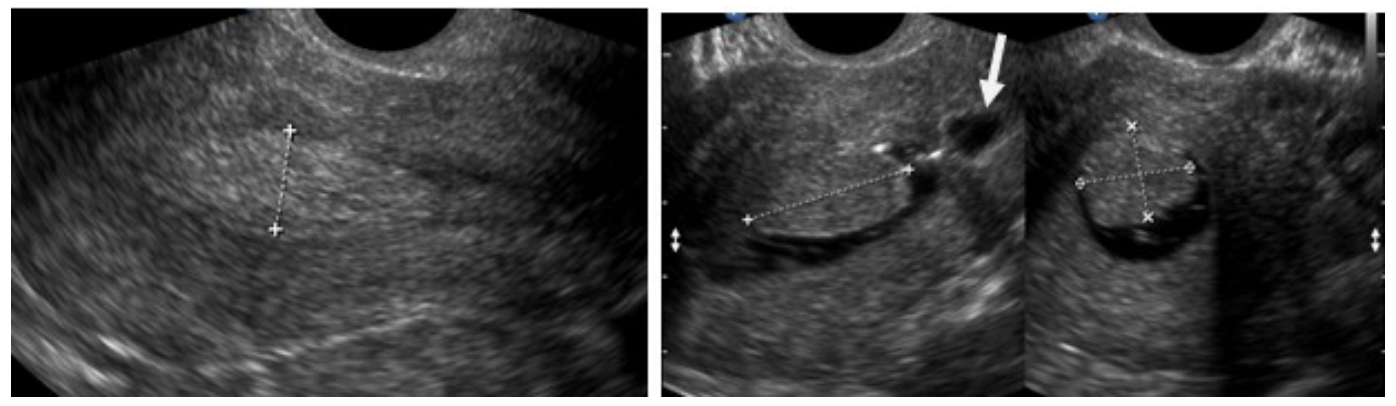

Figure 8. 32 years old patient who presented with metrorrhagia. Right: normal TVS with endometrial thickness of $10.9 \mathrm{~mm}$. Left: same patient's SHG shows a sessile endometrial lesion at the anterior wall of the uterine cavity. Note the balloon of the Foleys Catheter (arrow) 

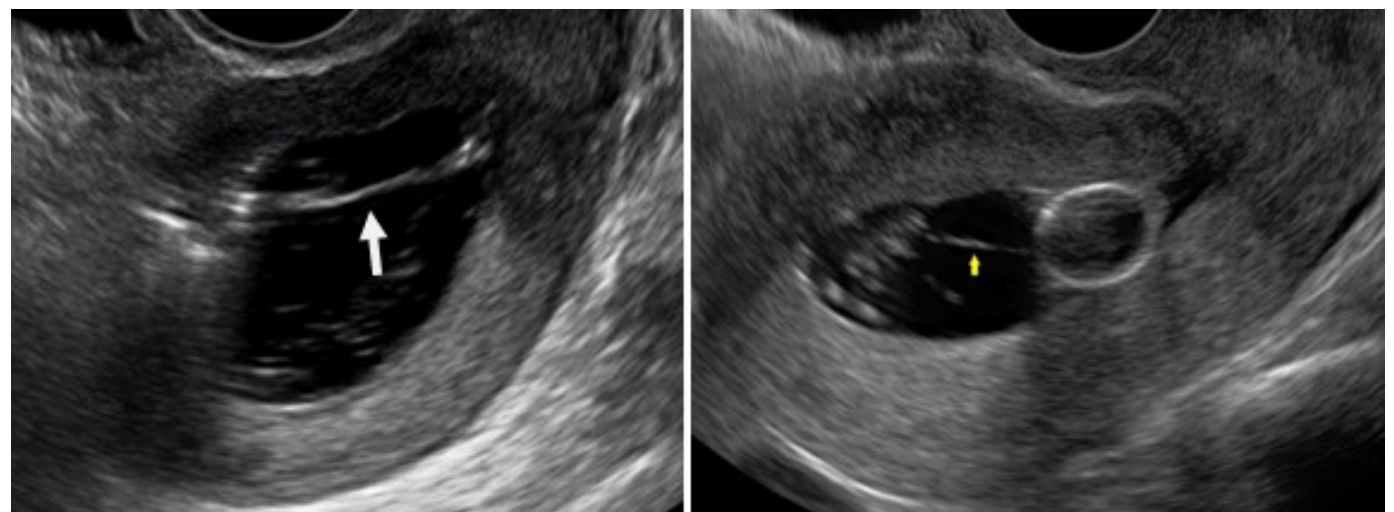

Figure 9. Above 2 were patients presenting with oligomenorrhea. Both the 2 TVS results were normal. SHG showed thin echogenic bands within the cavity. Diagnosis of partial synechiae was made
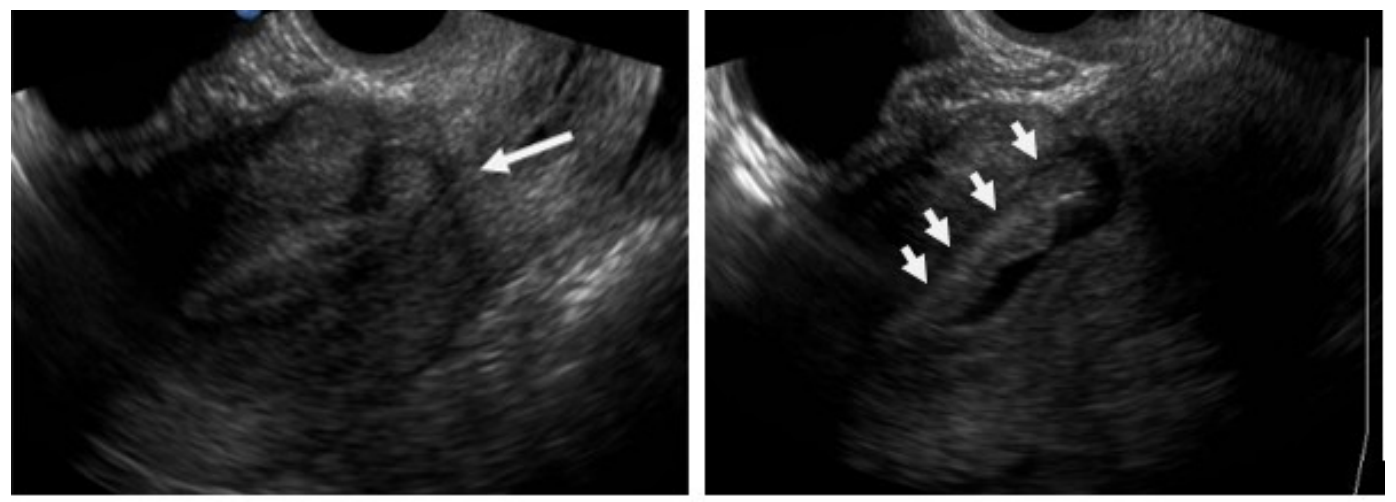

Figure 10. Right: TVS showing well defined round lesion which was isoechoic to the endometrium (white arrow). Left: SHG reveals a sessile lesion larger than assumed on TVS ( white arrows)
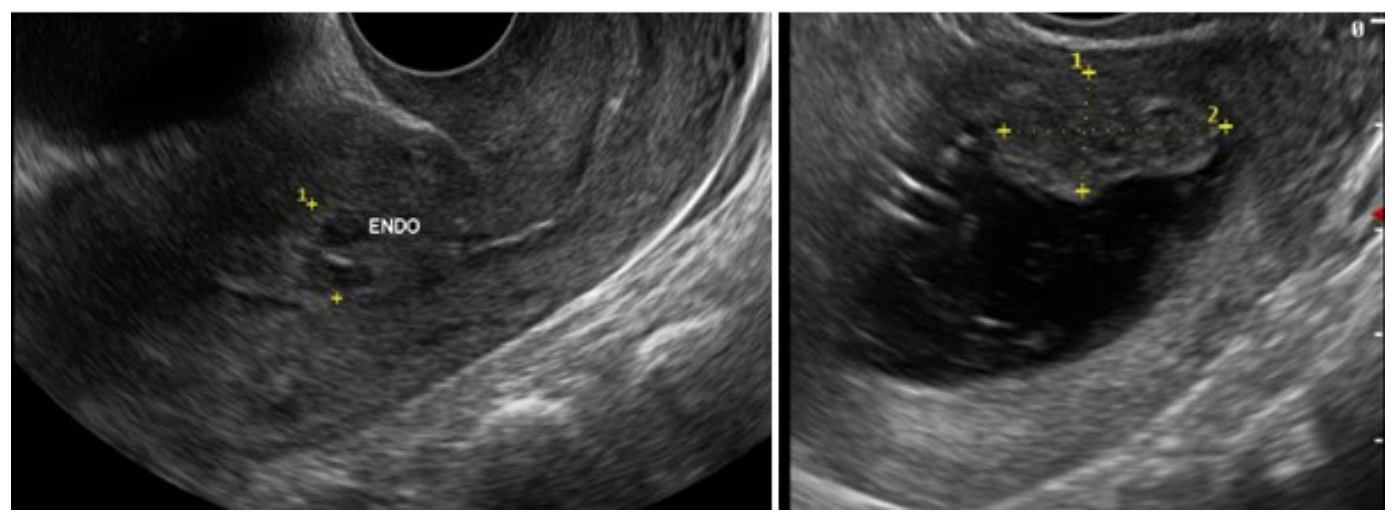

Figure 11. Left: TVS reveals endometrium which is slightly heterogenous. No definite lesion seen. Right: SHG reveals a mass within the uterine cavity

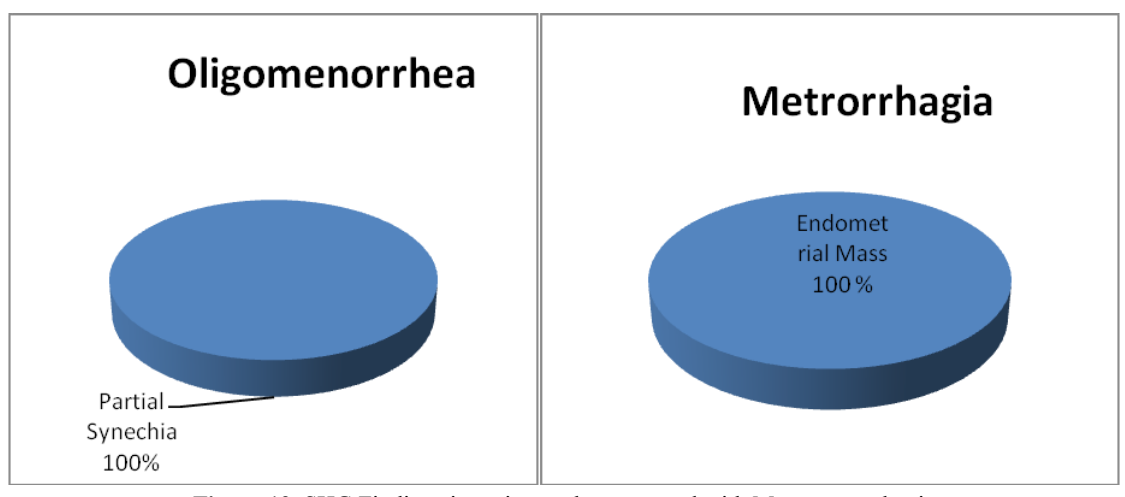

Figure 12. SHG Findings in patients who presented with Menometrorrhagia

In this study, all our patients with polymenorrhea and hypomenorrhea had normal SHG findings 
Table 1. The number of normal and abnormal SHG in all the clinical presentations and the percentage of abnormalities in each clinical presentation

\begin{tabular}{|l|l|l|l|}
\hline $\begin{array}{l}\text { Clinical } \\
\text { Presentation }\end{array}$ & Normal SHG & Abnormal SHG & $\begin{array}{l}\text { \% Of Pathology } \\
\text { Detected on SHG }\end{array}$ \\
\hline Menometrorrhagia & 14 & 4 & 22.22 \\
\hline Hypomenorrhea & 5 & 0 & 00.00 \\
\hline Menorrhagia & 16 & 6 & 27.27 \\
\hline Metrorrhagia & 16 & 1 & 05.88 \\
\hline Oligomenorrhea & 16 & 2 & 08.00 \\
\hline Polymenorrhea & 7 & 0 & 00.00 \\
\hline
\end{tabular}

Table 2. Comparison between clinical presentation, TVS findings and SHG Findings in abnormal SHG cases

\begin{tabular}{|l|l|l|}
\hline $\begin{array}{l}\text { PRESENTING } \\
\text { SYMPTOMS }\end{array}$ & TVS FINDINGS & SHG FINDING \\
\hline Menometrorrhagia & Endometrial hyperplasia & Endometrial hyperplasia \\
\hline Menometrorrhagia & Distorted endometrium & Submucosal Fibroid \\
\hline Menometrorrhagia & Endometrial hyperplasia & Normal Endometrium \\
\hline Menometrorrhagia & Loculated fluid in endometrium & Subendoetrial cyst \\
\hline Menorrhagia & Endometrial hyperplasia & Endometrial hyperplasia \\
\hline Menorrhagia & Normal & Endometrial Mass \\
\hline Menorrhagia & Endometrial hyperplasia & Endometrial hyperplasia \\
\hline Menorrhagia & Endometrial hyperplasia & Endometrial hyperplasia \\
\hline Menorrhagia & Floating clot & Floating clot \\
\hline Menorrhagia & Endometrial hyperplasia & Normal \\
\hline Menorrhagia & Endometrial hyperplasia & Endometrial Mass \\
\hline Metrorrhagia & Normal & Endometrial Mass \\
\hline Oligomenorrha & Normal & Partial synechiae \\
\hline Oligomenorrha & Normal & Partial synechiae \\
\hline
\end{tabular}

painful with minimal cost, and can be performed easier, faster and with more safety $[23,24]$. Hysteroscopy also does not contribute in the evaluation of myometrial or ovarian pathology.

The optimal timing for SHG depends on the clinical presentation. In a woman with regular menstrual cycles, SHG is typically done early in the follicular phase of the cycle, after cessation of menstrual flow, but not later than day the 10 of the cycle [25]. A thin endometrium also improves the visualization of focal lesions such as polyps which are best seen when they are surrounded by a thin postmenstrual endometrium [25]. The secretory phase is avoided because folds in the endometrial lining can mimic small fibroids or polyps, or focal areas of endometrial hyperplasia [25]. When the bleeding is irregular, and the above rules cannot be applied, then the SHG should be performed soon after the bleeding has stopped $[26,27]$.

In this research we assessed the SHG findings in patients presenting with clinical symptoms of AUB. According to our study, SHG was able to detect abnormalities in patients with AUB whose initial TVS studies showed normal or equivocal findings. TVS alone managed to detect abnormalities in $9 \%$ of the patients in the study group. Out of these, $38 \%$ had a diagnosis confirmed by SHG. The remaining $63 \%$ gave either a false or an equivocal finding. Of all the $8 \%$ of the cases reported as normal findings on TVS turned out to have pathology seen on SHG. According to the study by Jeong-ah Ryu et al, TVS has a positive predictive value of $83.0 \%$ and a negative predictive value of $39.3 \%$ [14].

Menorrhagia was the commonest symptom (25\%) and the most common lesion was endometrial hyperplasia (43\%) followed by endometrial mass (29\%). According to another study [22], commonest symptom was menorrhagia (73\%) and the most common finding was intramural fibroids at $42 \%$ [22].

SHG has also shown to be better in differentiating between large intramural and submucosal fibroids. TVS failed to locate the exact site of fibroid in $29 \%$ of the cases in our study. McGraw Hill [21] in his study found that TVS was not able to determine the location of fibroid in $10 \%$ of the cases, while SHG was able to make exact measurement and location of the fibroids.

Our study showed that SHG is more sensitive for detecting endometrial and subendometrial lesions than TVS alone. In a metaanalysis review on perimenopausal women with AUB and comparing it to hysteroscopy [24] suggested that SHG is an accurate means of evaluating uterine cavity in perimenopausal women with substantial cost savings as it can replace diagnostic hysteroscopy.

TVS may not distinguish endometrial hyperplasia from polyps [28]. This is because both of these 2 conditions can cause thickening of the endometrium. Both are also hyperechoic and can contain cystic spaces. SHG can distinguish focal lesions from diffuse thickening [28]. In our study $40 \%$ of the cases of endometrial hyperplasia on TVS proved to be not all endometrial hyperplasia. One was confirmed to be endometrial thickness within normal limits and another showed an endometrial mass.

Endometrial lesions were seen at all age groups. Determination of the exact nature of the lesion was to be done with pathological correlation. All the cases of partial synechiae were associated with clinical presentation of oligomenorrhea.

Recent development and improvement of 3D TVS studies of the endometrium has enabled better visualization and thus characterization of endometrium pathology. It has the capability of distinguishing endometrial hyperplasia versus endometrial polyps and define location of submucosal fibroids. Unfortunately, the 3D TVS probe is not available locally.

\section{Conclusion}

Although TVS is a simple, minimally invasive low-cost technique initially used in evaluating AUB, it is not conclusive since a normal TVS study does not always exclude endometrial pathology. SHG can detect abnormalities in an otherwise normal TVS. In addition, SHG is useful to further evaluate a positive finding on TVS. SHG is also relatively cheaper in comparison to hysteroscopy. For this reason, SHG is recommended to be used in combination with TVS as an initial investigation of choice in patients presenting with AUB.

\section{References}

1. Marret H, Fauconnier A, Chabbert-Buffet N, Cravello L, Golfier F, et al. (2010) Clinical practice guidelines on menorrhagia: management of abnormal uterine bleeding before menopause. Eur J Obstet Gynecol Reprod Biol 152: 133-137. [Crossref]

2. Bazot M, Robert Y (2008) [Diagnostic imaging of menometrorrhagia]. J Gynecol Obstet Biol Reprod (Paris) 37 Suppl 8: S334-342. [Crossref]

3. Gervaise A (2008) [Hierarchy for diagnostic and etiological management in menometrorrhagia]. J Gynecol Obstet Biol Reprod (Paris) 37 Suppl 8: S349-355. [Crossref]

4. Choudry A, Shukr I, Khan S, Hafeez H, Jamal S, et al. (2010) Acceptability and accuracy of saline infusion sonohysterography in women with postmenopausal bleeding. $J$ Coll Physicians Surg Pak 20: 571-575. [Crossref]

5. Gumus II, Keskin EA, Kilic E, Aker A, Kafali H, et al. (2008) Diagnostic value of hysteroscopy and sonohysterography in endometrial abnormalities in asymptomatic postmenopausal women. Arch Gynecol Obstet 278: 241-244. [Crossref]

6. Bennett GL, Andreotti RF, Lee SI, Dejesus Allison SO, Brown DL, et al (2011) ACR Appropriateness Criteria on Abnormal Vaginal Bleeding. J Am Coll Radiol 8: 460-468. [Crossref]

7. de Albuquerque LG, Hardy E, Bahamondes L (2006) [Hysterosonography: evaluation of the uterine cavity in women with abnormal uterine bleeding]. Rev Assoc Med Bras (1992) 52: 247-250. [Crossref] 
8. Ryan S, McNicholas M, Eustace S (2004) Anatomy for diagnostic imaging (2nd Edn). Saunders, USA.

9. Netter FH (2006) Atlas of human anatomy (4th Edn). Saunders, USA.

10. Jonathan S Berek. Berek \& Novak's Gynecology. (14th Edn). Lippincott Williams \& Wilkins;2007. [Crossref]

11. Noyes RW, Hertig AW, Rock J (1950) Dating the endometrial biopsy. Fertil Steril 1: 3-25.

12. Ferenczy A, Bertrand G, Gelfand MM (1979) Proliferation kinetics of human endometrium during the normal menstrual cycle. Am J Obstet Gynecol 133: 859-867. [Crossref]

13. Carol M. Rumack, Stephanie R. Wilson, J. William Charboneau. (2005) Diagnostic ultrasound. (3rd Edn.) Elsevier Mosby. [Crossref]

14. Ryu JA, Kim B, Lee J, Kim S, Lee SH, et al. (2004) Comparison of transvaginal ultrasonography with sonohysterography as a screening method in patients with abnormal uterine bleeding. Korean J Radiol 5: 39-46. [Crossref]

15. Laifer-Narin S, Ragavendra N, Parmenter EK, Grant EG (2002) False-Normal Appearance of the Endometrium on Conventional Transvaginal Sonography Comparison with Saline Sonohysterography. AJR Am J Roentgenol 178: 129-133. [Crossref]

16. Baldwin MT (1999) Transvaginal US and Sonohysterography in Postmenopausal Women with Breast Cancer Receiving Tamoxifen: Correlation with Hysteroscopy and Pathologic Study. Radiographics 19: 927-935.

17. Ryan GL, Syrop CH, Van Voorhis BJ (2005) Role, epidemiology, and natural history of benign uterine mass lesions. Clin Obstet Gynecol 48: 312-324. [Crossref]

18. Clevenger-Hoeft M, Syrop CH, Stovall DW, et al. (1999) Sonohysterography in premenopausal women with and without abnormal bleeding. Obstet Gynecol 94: 516520. [Crossref]
19. DeWaay DJ, Syrop CH, Nygaard IE, Davis WA, Van Voorhis BJ (2002) Natural history of uterine polyps and leiomyomata. Obstet Gynecol 100: 3-7. [Crossref]

20. Savelli L, De Iaco P, Santini D, Rosati F, Ghi T, et al. (2003) Histopathologic features and risk factors for benignity, hyperplasia, and cancer in endometrial polyps. $A m J$ Obstet Gynecol 188: 927-931. [Crossref]

21. Alan H. Decherney, Lauren Nathan, T. Murphy, Neri Laufer (2007) Current diagnosis and treatment Obstetrics and gynecology. 10th Edition: McGraw- Hill. [Crossref]

22. Reddi Rani P, Lakshmikantha G (2010) TransvaginalSonography (TVS) and Saline Infusion Sonohysterography (SIS) in the Evaluation of Abnormal Uterine Bleeding (AUB). J Obstet Gynecol 60: 511-515.

23. Goldstein SR, Zeltser I, Horan CK, Snyder JR, Schwartz LB (1997) Ultrasonographybased triage for perimenopausal patients with abnormal uterine bleeding. Am J ObstetGynecol 177: 102-108. [Crossref]

24. de Kroon CD, Jansen FW (2006) Saline infusion sonography in women with abnorma uterine bleeding: An update of recent findings. Curr Opin Obstet Gynecol 18: 653-657. [Crossref]

25. Widrich T, Bradley LD, Mitchinson AR, Collins RL (1996) Comparison of saline infusion sonography with office hysteroscopy for the evaluation of the endometrium. Am J Obstet Gynecol 174: 1327-1334. [Crossref]

26. Berridge DL, Winter TC (2004) Saline infusion sonohysterography: Technique, indications, and imaging findings. J Ultrasound Med 23: 97-112. [Crossref]

27. Sohaey R, Woodward P (1999) Sonohysterography: technique, endometrial findings, and clinical applications. Semin Ultrasound CT MR. 20: 250-258. [Crossref]

28. Kupfer MC, Schiller VL, Hansen GC, Tessler FN (1994) Transvaginal sonographic evaluation of endometrial polyps. J Ultrasound Med 13: 535-539. [Crossref]

Copyright: $@ 2018$ Mohamed SM. This is an open-access article distributed under the terms of the Creative Commons Attribution License, which permits unrestricted use, distribution, and reproduction in any medium, provided the original author and source are credited. 